\title{
CORRECTION
}

\section{Correction: Oxygen desaturations in the early neonatal period predict development of bronchopulmonary dysplasia}

Karen D. Fairchild, V. Peter Nagraj, Brynne A. Sullivan, J. Randall Moorman and Douglas E. Lake

Pediatric Research (2020) 88:820; https://doi.org/10.1038/s41390-020-0821-x

Correction to: Pediatric Research (2019) 85, 987-993 https://doi.org/ 10.1038/s41390-018-0223-5, published online 29 October 2018.

In the original version of this article, two funding sources were inadvertently omitted by the publisher. The following text has now been added under the heading 'Acknowledgements': "This study was funded by National Institutes of Health HD072071 and HD064488". This has been corrected in both the PDF and HTML versions of the article. 